\title{
COMMENTARY
}

\section{The puzzle of long-term morbidity after critical illness}

\author{
Hannah Wunsch*1 and Derek C Angus ${ }^{2}$ \\ See related research by Cuthbertson et al., http://ccforum.com/content/14/1/R6
}

\begin{abstract}
Data continue to emerge demonstrating the poor quality of life of ICU survivors in the months and years following critical illness. In this issue of Critical Care, Cuthbertson and colleagues present new data on quality of life from a cohort of ICU survivors who were followed for 5 years. They found that survivors had poor physical quality of life and low quality adjusted lifeyears in comparison to age-adjusted norms, describing the long-term impact of critical illness as similar to a co-morbidity. Studies are now needed that seek to identify potentially modifiable factors both during and following an ICU admission to allow for eventual improvement in long-term morbidity. Such studies will likely need to incorporate extensive planning for data collection, as well as coordinated linkage with other available datasets that include substantial amounts of patient information from outside of the ICU.
\end{abstract}

Over the past 10 years we have learned that some ICU patients remain at elevated risk for many problems in the months following critical illness. These problems may occur in the first few months, or even the first year after a critical illness, but what about in the longer-term? In this issue of Critical Care, Cuthbertson and colleagues [1] provide data from an ambitious single-center study in Scotland that followed critical care survivors for 5 years, measuring physical and mental quality of life at various time-points. These are precious data as few studies have managed to follow patients for such an extended period of time. Using the established SF-36 and EQ-5D questionnaires, as well as general survey questions, they found that ICU admission was associated with poor

*Correspondence: hw2125@columbia.edu

'Division of Critical Care, Department of Anesthesiology, Columbia University, 622 West 168th St, New York, NY 10032, USA

Full list of author information is available at the end of the article physical quality of life and low quality adjusted life-years after 5 years. Encouragingly, they did find that the mean mental scores after 6 months were similar to population norms. Because of the overall lower quality of life in comparison to age-adjusted norms, the authors suggest that surviving an admission to the ICU may warrant acknowledgement of its long-term physical impact on patients, along the lines of other 'true' chronic medical conditions.

It is important to note that this study did not include a specific control population. Instead, the authors compared outcomes in their ICU cohort to known age-adjusted norms for the set of standard quality of life questionnaires employed. For cohort studies, the ideal is to have information not only on quality of life post-ICU, but also information on pre-ICU functional status, and an appropriate matched control group for comparison - a tall order. Studies of morbidity and mortality after critical care are also difficult due to the frequent 'loss to follow-up.' This study was only able to provide data on 195 out of 300 patients enrolled (65\%) for the entire 5 years. The authors provide imputed data to suggest that the findings would not substantially change with the additional survivors, but most methods to adjust for loss-to-follow-up are least robust when potentially informative censoring is occurring, which is very likely in studies of ICU survivors.

Data from cohort studies examining mortality after critical illness are mixed with regard to whether or not there is a residual long-term risk of death [2-4]. But taken together with other studies, primarily of subgroups of patients such as those with the acute respiratory distress syndrome [5,6], and severe sepsis [7], the data of Cuthbertson and colleagues provide a consistent picture of the risk of morbidity, demonstrating that many ICU survivors continue to struggle with decreased quality of life. These post-ICU sequelae include inability to work [5], post-traumatic stress disorder [8], cognitive dysfunction [9], depression [10], and other alterations in lifestyle associated with physical disability [11].

The questions become what, exactly, are the cause of these decrements, whether these factors are specific to all ICU patients or are only seen in specific subgroups, and 
whether some of these factors are modifiable with the ultimate goal of interventions to improve these outcomes. While standard measures of quality of life, such as the SF-36, are important because they are well validated, they are limited in that they do not provide information that allows us to understand the mechanisms leading to these decrements in quality of life. To identify these factors, we need to improve our understanding of the interplay among pre-existing conditions, specific events and care provided within the ICU, and both short- and long-term functional status.

Assessing the changes in quality of life associated with critical illness is a uniquely frustrating venture. Critical illness combines (often) unplanned admission with illness severe enough that patients are not able to provide information themselves, sometimes causing intensivists to liken their work to that of pediatricians or veterinarians, gathering information from charts and family members. How, then, to establish the physical and mental quality of life of a patient prior to admission? One option would be to follow a cohort of patients, measuring quality of life, and waiting for critical illness to occur. Unfortunately, the low frequency of critical illness in the population makes this a difficult study design [12]. The alternative, chosen by Cuthbertson and colleagues, was to use estimates of pre-illness quality of life generated by family members. While this approach certainly represents a good option, it is still a proxy for true measures, and we know from other work that family members often underestimate reported quality of life of patients when the two measures are compared [13].

Further studies that involve long-term follow-up are clearly needed, and data from longer than 1 year seem essential. A few studies have been able to leverage other pre-existing data sources to supplement ICU-specific data $[14,15]$. Such research requires enormous foresight, to allow for appropriate data collection, as well as integration with other data systems. To ultimately provide answers that can lead to improvements, research in this area should involve reaching well beyond traditional boundaries of intensive care to out-patient settings, and making use of other rich clinical data sources, to gain a clearer picture of the lives of all critically ill patients pre and post-ICU.

\section{Author details}

'Division of Critical Care, Department of Anesthesiology, Columbia University, 622 West 168th St, New York, NY 10032, USA

${ }^{2}$ The CRISMA Laboratory (Clinical Research, Investigation, and Systems

Modeling of Acute Illness), Department of Critical Care Medicine, University of Pittsburgh, Pittsburgh, PA 15261, USA

\section{Competing interests}

The authors declare that they have no competing interests.

Published: 16 February 2010

\section{References}

1. Cuthbertson BH, Roughton S, Jenkinson D, MacLennan G, Vale L: Quality of life in the five years after intensive care: a cohort study. Crit Care 2010, 14:R6.

2. Keenan SP, Dodek P, Chan K, Hogg RS, Craib KJ, Anis AH, Spinelli JJ: Intensive care unit admission has minimal impact on long-term mortality. Crit Care Med 2002, 30:501-507.

3. Weycker D, Akhras KS, Edelsberg J, Angus DC, Oster G: Long-term mortality and medical care charges in patients with severe sepsis. Crit Care Med 2003, 31:2316-2323.

4. Wright JC, Plenderleith L, Ridley SA: Long-term survival following intensive care: subgroup analysis and comparison with the general population Anaesthesia 2003, 58:637-642.

5. Herridge MS, Cheung AM, Tansey CM, Matte-Martyn A, Diaz-Granados N, Al-Saidi F, Cooper AB, Guest CB, Mazer CD, Mehta S, Stewart TE, Barr A, Cook D, Slutsky AS; Canadian Critical Care Trials Group: One-year outcomes in survivors of the acute respiratory distress syndrome. N Engl J Med 2003, 348:683-693.

6. Angus DC, Musthafa AA, Clermont G, Griffin MF, Linde-Zwirble WT, Dremsizov TT, Pinsky MR: Quality-adjusted survival in the first year after the acute respiratory distress syndrome. Am J Respir Crit Care Med 2001, 163:1389-1394.

7. Heyland DKM, Hopman WB, Coo HB, Tranmer JR, McColl MAP: Long-term health-related quality of life in survivors of sepsis. Short Form 36: A valid and reliable measure of health-related quality of life. Crit Care Med 2000, 28:3599-3605.

8. Davydow DS, Gifford JM, Desai SV, Needham DM, Bienvenu OJ: Posttraumatic stress disorder in general intensive care unit survivors: a systematic review. Gen Hosp Psychiatry 2008, 30:421-434.

9. Hopkins RO, Jackson JC: Long-term neurocognitive function after critical illness. Chest 2006, 130:869-878

10. Davydow DS, Gifford JM, Desai SV, Bienvenu OJ, Needham DM: Depression in general intensive care unit survivors: a systematic review. Intensive Care Med 2009, 35:796-809.

11. Chelluri L, Im KA, Belle SH, Schulz R, Rotondi AJ, Donahoe MP, Sirio CA Mendelsohn AB, Pinsky MR: Long-term mortality and quality of life after prolonged mechanical ventilation. Crit Care Med 2004, 32:61-69.

12. Kersten A, Milbrandt EB, Rahim MT, Watson RS, Clermont G, Angus DC, Linde-Zwirble WT: How big is Critical Care in the U.S.? [Abstract]. Crit Care Med 2003, 31:A8

13. Jordan-Marsh M: The SF-36 Quality-of-Life Instrument: updates and strategies for critical care research. Crit Care Nurse 2002, 22:35-43.

14. Williams TA, Dobb GJ, Finn JC, Knuiman MW, Geelhoed E, Lee KY, Webb SA: Determinants of long-term survival after intensive care. Crit Care Med 2008 36:1523-1530.

15. Yende S, Angus DC, Ali IS, Somes G, Newman AB, Bauer D, Garcia M, Harris TB, Kritchevsky SB: Influence of comorbid conditions on long-term mortality after pneumonia in older people. J Am Geriatr Soc 2007, 55:518-525.

doi:10.1186/cc8863

Cite this article as: Wunsch H, Angus DC: The puzzle of long-term morbidity after critical illness. Critical Care 2010, 14:121. 